\title{
Prehospital emergency rapid sequence induction of anaesthesia
}

\author{
Colin A Graham, Alastair D McR Meyer
}

\begin{abstract}
Objective-To determine the number of and reasons for rapid sequence inductions done by accident and emergency (A\&E) doctors out of hospital as part of the activities of the MEDIC 1 Flying Squad. "Rapid sequence induction" was defined as any attempted endotracheal intubation accompanied by use of drugs to assist intubation and ventilation, including opiates, benzodiazepines, intravenous and topical anaesthetics, and neuromuscular blocking drugs.

Methods-Retrospective study of all MEDIC 1 and A\&E records over the period 1 February 1993 to 28 February 1996 (37 months). The anaesthetic technique used, drugs used, complications, difficulties, reasons for induction out of hospital, and grade of doctor performing the technique were determined.

Results-Various anaesthetic techniques were used to secure the airway definitively by endotracheal intubation. Several difficulties were encountered in the prehospital setting, all of which were dealt with successfully.

Conclusions-The lack of complications related to rapid sequence induction in prehospital care suggests that this technique is safe when done by $A \& E$ doctors on appropriate patients.
\end{abstract}

$(\mathcal{A}$ Accid Emerg Med 1997;14:219-221)

Keywords: rapid sequence induction; emergency anaesthesia; accident flying squads; prehospital care; definitive airway

Definitive airway control by endotracheal intubation and mechanical ventilation is a primary function of the Royal Infirmary of Edinburgh's MEDIC 1 accident flying squad. ${ }^{1}$ The need for rapid sequence induction of anaesthesia and artificial ventilation arises often in the prehospital setting because of respiratory failure secondary to medical problems, airway compromise in trauma patients, or need for ventilation of head injured patients (who are often multiply injured). MEDIC 1 team leaders (consultants, senior registrars, and registrars from the accident and emergency ( $A \& E$ ) department) perform rapid sequence induction at the scene before transporting the patient. The decision to undertake rapid sequence induction in the prehospital setting lies entirely with the MEDIC 1 team leader.

It is well recognised that securing the airway is the keystone of trauma management ${ }^{2-6}$ and rapid sequence induction can be safely used at the scene, ${ }^{78}$ although it is uncommonly performed in the United Kingdom and there have been very few studies documenting rapid sequence induction in the prehospital setting in this country.

In the United Kingdom, rapid sequence induction can only be performed by medical practitioners; however, rapid sequence induction techniques are used in the USA by paramedics, ${ }^{5}$ and heavy sedation (but not neuromuscular blocking drugs) is used by paramedics in Australia. ${ }^{10}$

Rapid sequence induction usually consists of preoxygenation followed by a suitable dose of intravenous induction agent (for example, thiopentone, etomidate, propofol, or fentanyl) followed immediately by a short acting depolarising neuromuscular blocking drug (suxamethonium). The airway is immediately secured by endotracheal intubation and ventilation is started. A non-depolarising neuromuscular blocking drug (for example, pancuronium, vecuronium, or atracurium) is then given, together with appropriate sedation (for example, propofol infusion/opiate/benzodiazepine). ${ }^{11}$ These techniques are often modified in the prehospital setting according to the conditions encountered.

This retrospective study was undertaken to determine the frequency and type of prehospital rapid sequence induction performed by the Edinburgh Accident Flying Squad (MEDIC 1) as part of its activities over the last three years. The study did not to include descriptions of, or recommendations for, specific anaesthetic techniques for use in prehospital care.

\section{Methods}

The study period extended over 37 months, from 1 February 1993 to 28 February 1996 inclusive. Rapid sequence induction for the purposes of this study was defined as any attempted endotracheal intubation accompanied by use of drugs to assist intubation and ventilation, including opiates, benzodiazepines, intravenous and topical anaesthetics, and neuromuscular blocking drugs. All attempted intubations performed in the prehospital setting by the MEDIC 1 team leader and fulfilling the above definition were included. A retrospective case note review was performed, using details from the MEDIC $1 \log$ book, $A \& E$ records, and inpatient records where necessary. Details noted for each patient included the anaesthetic technique used, drugs used, complications, difficulties encountered, indications for out of hospital induction, and grade of doctor undertaking the procedure. 


\section{Results}

Twenty six rapid sequence inductions were performed over the study period, an average of 0.7 per month. There were 640 requests for the MEDIC 1 accident flying squad over the study period and 183 endotracheal intubations were performed by the MEDIC 1 team leader: 35\% of rapid sequence inductions $(9 / 26)$ were done by $A \& E$ consultants, $19 \%(5 / 26)$ by senior registrars, and $46 \%(12 / 26)$ by registrars. In one patient no further details of drugs or methods used were obtainable, and this patient was excluded from further analysis. Thiopentone sodium was used in $52 \%$ of cases (13/25), Cyclimorph (morphine tartrate + cyclizine tartrate) in $16 \%(4 / 25)$, diazepam in $8 \%(2 / 25)$, a diazepam and Cyclimorph combination in $8 \%$ $(2 / 25)$, and topical lignocaine to the vocal cords in $4 \%(1 / 25) ; 12 \%(3 / 25)$ were intubated without induction agents and subsequently paralysed to allow mechanical ventilation.

A depolarising neuromuscular blocking drug (suxamethonium) was used in $64 \%(16 / 25)$ to assist tracheal intubation. A non-depolarising neuromuscular blocking drug (pancuronium) was used in $64 \%$ of the cases (16/25) to allow mechanical ventilation in transit.

Twenty per cent of rapid sequence inductions $(5 / 25)$ were performed for medical emergencies (status epilepticus, acute severe asthma, left ventricular failure [two patients] and tricyclic overdose), and the remainder were performed on trauma patients. Indications for intubation of trauma patients included an inadequate airway $(70 \%, 14 / 20)$, inadequate ventilation $(85 \%, 17 / 20)$, head injury $(85 \%, 17 / 20)$, and chest injuries $(25 \%$, $5 / 20)$. There was considerable overlap of these categories in individual patients as many of them were multiply injured.

Difficulties were encountered in 13 trauma patients $(65 \%)$ who were intubated with hard cervical collars in place. These patients had their collars removed with in-line cervical immobilisation during endotracheal intubation to facilitate mouth opening for visualisation of the cords. Once the airway was secured the collar was replaced before transfer.

Very high inflation pressures were a problem in one critically ill asthmatic patient. One patient with severe upper airway burns and impending airway obstruction (Glasgow coma score $=3 / 15$ ) was given morphine and suxamethonium and oral endotracheal intubation was attempted. It was impossible to view the cords on two attempts and as manual ventilation was becoming more difficult a surgical cricothyrotomy was performed successfully. Ventilation then proceeded without further incident.

No patient acutely deteriorated as a result of prehospital rapid sequence induction.

\section{Discussion}

These results show that suitably trained and experienced $A \& E$ doctors can safely undertake rapid sequence inductions for definitive airway control and controlled ventilation in the prehospital situation. McBrien et al showed that $A \& E$ doctors could safely perform these tasks in the resuscitation room in $\mathrm{A} \& \mathrm{E}$, and it appears that the techniques can also be used successfully out of hospital. It is difficult to determine if the on-scene times were lengthened by prehospital rapid sequence induction, although one would assume that they were to some extent. It was not possible to determine times from this retrospective study. Rapid sequence induction was performed at the discretion of the MEDIC 1 team leader. The decision to perform it was made solely on clinical grounds (need for definitive airway control and/or ventilation) and was irrespective of the distance from hospital.

All MEDIC 1 team leaders undertaking prehospital rapid sequence induction had been trained to perform rapid sequence induction in the resuscitation room in $A \& E$ under the guidance of consultants in $A \& E$ medicine and anaesthesia. However, the majority of team leaders also had at least three months of formal training in anaesthesia as part of higher professional training in $\mathrm{A} \& \mathrm{E}$ medicine.

Endotracheal intubation has been found to influence patient outcome in prehospital care. ${ }^{6}$ It has never been shown conclusively whether prehospital rapid sequence inductions to facilitate intubation are associated with improved outcome. However, the common principle of securing the airway as the top priority in any resuscitation remains, and therefore it is likely that prehospital intubation with or without rapid sequence induction will be beneficial to the patient. The use of a neuroanaesthetic technique for the intubation of head injured patients will reduce acute rises in intracranial pressure $^{12}$ and is therefore likely to improve outcome in this large subgroup of patients who had a prehospital rapid sequence induction.

We believe that prehospital rapid sequence induction has a significant role to play in the early management of both medical and trauma patients, and it would appear from this study that it can be safely applied by appropriately trained and experienced $A \& E$ doctors.

\section{CONCLUSION}

Prehospital rapid sequence induction to facilitate definitive airway control by endotracheal intubation and controlled ventilation can safely be given to selected patients by appropriately trained accident and emergency staff. The lack of complications related to prehospital rapid sequence induction suggests that this technique is safe. The precise benefits of the procedure remain to be quantified by prospective study.

We would like to thank Dr K Little, Dr C E Robertson, and Mr D J Steedman for permission to report on their patients, and especially Dr Little for constructive criticism and help in the
preparation of this paper. We would also like to thank Ms Diana preparation of this paper. We would also like to thank Ms Diana prehospital data on trauma patients in this study.

1 Dark PM, Little K, Steedman DJ, Gordon MWG, Robertson CE. An objective analysis of an accident flying squad. Scot Med J 1990;35:73-6.

2 McBrien ME, Pollok AJ, Steedman DJ. Advanced airway control in trauma resuscitation. Arch Emerg Med 1992;9: 177-80 
3 Royal College of Surgeons of England. Report of the Working Party on the Management of Patients with Major Injuries, 1988:14-19.

4 Pepe PE, Stewart RD, Copass MK. Prehospital management of trauma: a tale of three cities. Ann Emerg Med 1986;15:1484-90.

5 Hedges JR, Dronen SC, Feero S, Hawkins S, Syverud SA, Shultz B. Succinylcholine assisted intubations in prehospiShultz B. Succinylcholine assisted intubation

6 Stewart RD. Advances in prehospital immediate care. Resuscitation 1989;18(suppl):S13-20.

7 Syverud SA, Borron SW, Storer DL, Hedges JR, Dronen

Syverud SA, Borron SW, Storer DL, Hedges JR, Dronen SC, Braunstein LT, et al. Prehospital use of neuromuscular
blocking agents in a helicopter ambulance program. Ann blocking agents in a helicopter ambulance program. Ann

8 Vilke GM, Hoyt DB, Epperson M, Fortlage D, Hutton KC,
Rosen P. Intubation techniques in the helicopter. J Emerg Med 1994;12:217-24.

9 Heath KJ, Samra GS, Davis GE, Wilmink AB, Wilson AW. Blood pressure changes in head injury patients during prehospital anaesthesia with propofol. Injury 1994;25(suppl 2):S-B7-8.

10 Cameron PA, Flett K, Kaan E, Atkin C, Dziukas L. Helicopter retrieval of primary trauma patients by a paramedic helicopter service. Aust NZ J Surg 1993;63: 790-7.

11 Illingworth KA, Simpson KH. Anaesthesia and analgesia in emergency medicine. Oxford: Oxford University Press, 1994: 92-5.

12 Hinds CJ, Watson D. Intensive care: a concise textbook, 2nd ed. London: W B Saunders, 1996:330-1.

\section{Faculty of Accident and Emergency Medicine}

\section{Consultant appointments in A\&E, September 1996 to April 1997}

Dr G A Hobbs,

Dr A Anthony

Mr S Bhattacharya

Mr K A Bizos

Mr D Cartlidge

$\mathrm{Mr} \mathrm{T}$ Coats

Dr M Clancy

Mr A M Dalton

Mr H Dardouri

Mr G Davies

Mr T Daynes

Mr B Dorani

Mr L P Duane

Dr C V Egleston

Miss M Farrell-Roberts

Mr A Gleeson

Mr K K Gupta

Mr A Hamed

Mr K Hassan

Mr J Hayes

Mr D Hodgkinson

Mrs D Hulbert

Mr T R Jackson

Mr M Lavis

Dr S Mardel

Mr J McKeever

Mr M Morris

Ms J Nancarrow

Mr D Parkins

Mr V Sethkumar

Mr S Southworth

Mr M J Stuart

Mr A R Tabani

Dr J G B Thurston

Mr C Tovey

Mr N Rashid

Mr A M Schweikh

Mr W Smallman

Mr A Volans

Ms P Ward

Mr A Wass
Chertsey, Surrey

Alexander Healthcare Trust

Rochdale Healthcare Trust

Stoke Mandeville Hospital, Aylesbury

Glan Clwyd Hospital

Royal London Hospital, London E1

Southampton General Hospital

St Albans and Hemel Hempstead

Blackburn/Ribble Health

Royal London Hospital, London E1

Norfolk \& Norwich Hospital

Queen Elizabeth II Hospital, Gateshead

Royal Manchester Children's Hospital

Southampton General Hospital

William Harvey Hospital, Ashford

St George's Hospital, London SW 17

Good Hope Hospital, Sutton Coldfield

Cheviot \& Wansbeck Hospitals

Poole Hospital

Central Middlesex Hospital

Ipswich Hospital

West Middlesex University Hospital

Royal Hull Hospitals

Nevill Hall Hospital

Furness General Hospital

Greenwich Healthcare

Warwick Hospital

Blackburn/Ribble Health

City Hospital, Sunderland

Medway Hospital

Stepping Hill Hospital

North Manchester Healthcare

Good Hope Hospital, Sutton Coldfield

Dartford and Gravesham

Conquest Hospital, Hastings

Manor Hospital, Walsall

Grimsby Hospital

Lewisham Hospital

Scarborough Hospital

St Mary's Hospital, London W2

Pinderfields Hospital 